Jan Bentzen and Valdemar Smith

Alcohol consumption and liver cirrhosis mortality: New evidence from a panel data analysis for sixteen European countries

Department of Economics 
October 2010

\title{
Alcohol consumption and liver cirrhosis mortality: New evidence from a panel data analysis for sixteen European countries
}

\author{
Jan Bentzen (jb@asb.dk) \\ Valdemar Smith (vs@asb.dk) \\ Department of Economics \\ Aarhus School of Business, University of Aarhus \\ Hermodsvej 22 \\ 8230 Aabyhoj \\ Denmark
}

\begin{abstract}
:
Empirical evidence gives strong support to a close association between liver cirrhosis mortality and the intake of alcohol and most often a log-linear relationship is assumed in the econometric modeling. The present analysis investigates for unit roots in a panel data set for sixteen European countries - covering the period 1970-2006 - where both alcohol consumption and liver cirrhosis seem best described as trend-stationary variables. Therefore a fixed effects model including individual trends is applied in the analysis but also a more flexible non-linear functional form with fewer restrictions on the relationship between liver cirrhosis mortality and alcohol consumption is included. The conclusion is that the total level of alcohol consumption as well as the specific beverages - beer, wine and spirits - contributes to liver cirrhosis mortality, but the present study also reveals that directly addressing the question of panel unit roots and in this case subsequently applying a trend-stationary modeling methodology reduces the estimates of the impacts from alcohol consumption to liver cirrhosis. Finally, more restrictive alcohol policies seem to have positively influenced the country-specific development in cirrhosis mortality.
\end{abstract}

Key words: Alcohol consumption, Liver cirrhosis mortality, Trend-stationary panel data, Non-linear modelling.

JEL Code: I10 (Health economics).

The final version of the paper is forthcoming (with the same title) in Journal of Wine Economics, 2010, vol. 5(2), and please use this reference when citing. 


\section{Introduction}

The consumption of alcohol causes a number of health related diseases as well as other social costs, and among the detrimental effects liver cirrhosis is one of the most prominent as this eventually involves a high likelihood of premature mortality. The medical literature claims that a moderate level of alcohol consumption like a few drinks per day may even improve health conditions, primarily due to positive effects for heart diseases. Still, a high level of alcohol intake will imply negative net effects and thus, there is a so-called J-curve effect in relation to the health consequences of alcohol intake, de Lorimier (2000). For many countries the average level of alcohol consumption has exceeded a few drinks per day and therefore, the negative effects may outweigh the beneficial effects of population drinking and alcohol is usually regarded as the leading cause of liver cirrhosis, Gutjahr et al. (2001). Therefore, national health authorities come up with more explicit alcohol policies including 'advisory guidelines', e.g. the maximum number of drinks per week per individual (in some cases 21 drinks for men, less for women). In line with this a broad range of initiatives concerning alcohol policies is considered in relation to the European Union and the member states, Anderson and Baumberg (2006).

The present study focuses on an empirical analysis of the effects from the aggregate level of alcohol intake to the impact on cirrhosis mortality using aggregate data representing sixteen European countries. The data for cirrhosis mortality and alcohol consumption are both from the often used WHO database, as this is the most comprehensive source concerning international health data. During recent decades there has been a process of convergence in per capita consumption of alcohol among the European countries, where e.g. the level of alcohol consumption in some Southern European countries has declined relatively much. The frequency of alcohol related diseases like e.g. liver cirrhosis has changed significantly and in the same direction as the developments in alcohol consumption and, naturally, this has raised concerns about health implications. The present study focuses on an empirical analysis of the effects from the aggregate level of alcohol intake to the impact on cirrhosis mortality using aggregate data representing 
sixteen European countries. In line with this an important research question will be to further investigate the relationship between cirrhosis mortality and the specific beverages like beer, wine and spirits which may have differing impacts concerning health effects. The present study is organized with part 2 presenting the empirical findings from the present literature. Part 3 discusses the data and the econometric modelling procedures and part 4 and part 5 present the empirical findings. Finally, part 6 concludes the paper.

\section{Literature review and empirical findings}

Liver cirrhosis mortality and the relationship to alcohol consumption is an often addressed topic in numerous studies and in general, there is not much doubt about the clinical evidence concerning the harmful consequences from heavy drinking. The empirical evidence on the alcohol-induced cirrhosis mortality vary somewhat, and this is especially the case when trying to certify which of the specific beverages - beer, wine or spirits - that impacts on health conditions and eventually lead to mortality. Many of the empirical papers rely on individual micro data as an obvious point of departure concerning the choice of data and it is argued that causes are most easily detected by using individual-specific information on both alcohol consumption and liver cirrhosis mortality. Using aggregate data the connection between alcohol consumption and liver cirrhosis mortality has been detected in a number of empirical studies. Moreover it has been suggested that the variation in the average level of alcohol consumption also reflects the alcohol intake in groups of individuals with a high-risk level of e.g. liver cirrhosis. This also implies that heavy drinkers consume in a social context and are not confined to isolated drinking environments - otherwise, cirrhosis mortality should not be associated with the overall level of alcohol consumption in the population. An advantage associated with studies using aggregate data is that the impact from alcohol consumption to health or mortality is estimated, which is of relevance concerning alcohol policies, Norström and Ramstedt (2005).

From a methodological point of view aggregate studies have used differing econometric models and estimation techniques depending on the nature of data used. Most studies use 
either cross-section or time-series data and the conclusions are in general similar, i.e. significant effects of harmful health consequences from consumption of alcohol are present. Using time series data for fourteen European countries Ramstedt (2001) finds a significant effect on liver cirrhosis mortality rates and with a similar kind of data. Mills (2007) reaches the same conclusion for the UK. Norström and Ramstedt (2005) give a review of the empirical findings on the harmful effects of alcohol consumption and conclude that for fourteen Western European countries an increase in per capita alcohol consumption is significantly related to liver cirrhosis mortality - with the strongest effects in Northern Europe. A similar conclusion was reached for Canada as well as the individual provinces. For the USA spirits were found to have a cirrhosis impact in one study, Roizen et al. (1999). Another analysis, Kerr et al. (2000), which includes a panel data set for five English-speaking countries (USA, Canada, New Zealand, Australia, UK) finds liver cirrhosis to be associated with both the overall level of drinking and spirits consumption. An overview of methodologies and empirical findings can be found in Kerr et al. (2000), Gmel et al. (2001), Nordström and Skog (2001), Rehm and Gmel (2001), Room et al. (2005) and Antoñanzas et al. (2008).

With regard to the effects related to the specific beverages concerning liver cirrhosis the results from the literature on this topic differ relatively much. Some studies claim wine and spirits are both linked to the harmful effects and other studies only find one of the beverages most likely to cause cirrhosis; for a survey see Kerr et al. (2000). A recent study using time-series data - Mills (2007) - finds wine to be associated with cirrhosis in the UK, and beer and spirits to be of only minor importance. Heavy consumption of all three kinds of alcoholic beverages may cause liver cirrhosis and hence, there should be no beverage-specific effects - unless the beverages are related to specific drinking patterns and therefore cause the adverse health effects. The latter may be the case where spirits is primarily consumed by (elderly) men and without a simultaneous intake of food, where wine is much more likely to be enjoyed with regular meals.

For individual persons liver cirrhosis is usually caused by heavy drinking during a considerable number of years. Naturally, this will differ from person to person with a 
high level of individual variation, where e.g. women have a higher risk of developing liver cirrhosis for a given level of alcohol intake, Mumenthaler et al. (1999). Despite the gender-specific differences almost ninety per cent of the cirrhosis mortality cases are found in the male population. As discussed in Kerr et al. (2000) and Norström (1989), Norström and Ramstedt (2005) many of the studies using aggregate data often end up with a specification of the empirical model including only short lags from alcohol consumption to liver cirrhosis which appear inconsistent with the usually longdeveloping process of liver cirrhosis at the individual level. Therefore, the present study will focus on the question of beverage-specific cirrhosis mortality effects as well as the question of using longer lags of the alcohol consumption variable in the empirical estimations.

\section{Data and modelling the alcohol-liver cirrhosis relationship}

The data used in the present analysis are collected from the WHO Statistical Information System (WHOSIS, www.who.int) where the liver cirrhosis mortality is measured as the number of diceases per 100.000 persons in the total population ${ }^{1}$. The same WHO source also collects data on alcohol consumption and with the alcohol consumption variables measured in litres of pure alcohol per capita ( +15 years). Sixteen European countries are included in the analysis: Austria, Belgium, Denmark, Finland, France, Greece, Germany, Ireland, Italy, the Netherlands, Norway, Portugal, Switzerland, Spain, Sweden and the UK. The data for liver cirrhosis mortality go back to 1970 and for alcohol consumption also including the specific beverages - the data cover the period back to 1963 . The latter has been extended back in time to 1961 using data from World Drink Trends (1999) in order to have data covering a decade of alcohol consumption prior to 1970, where the cirrhosis mortality data are available in order to allow for lags in the empirical modelling procedure. The most recent available data are from 2006 and thus, these panel data generally cover the period 1970 to 2006 (with some variation because of missing values, and therefore the panel data set is unbalanced).

\footnotetext{
${ }^{1}$ Mortality data may involve some problems, e.g. due to differing coding practices among the countries concerning death causes, and also other diseases than liver cirrhosis may be present and causing death at the individual level.
} 
The data for 1980 and 2000 are presented in table 1 where a measure of the strictness of alcohol policies is also included. It is well-known that some countries, e.g. most of the Nordic countries, historically have adhered to very strict regulations. The 'restrictiveness' of alcohol policies, from Karlsson and Österberg (2001), is measured on a 1-20 scale and based on separate dimensions of alcohol policies with an increasing value indicating a more restrictive alcohol policy.

Table 1. Liver cirrhosis, alcohol consumption and alcohol policy in Europe.

\begin{tabular}{|c|c|c|c|c|c|c|}
\hline & \multicolumn{3}{|c|}{1980} & \multicolumn{3}{|c|}{2000} \\
\hline & $\begin{array}{l}\text { Liver cirr. } \\
\text { mortality }\end{array}$ & $\begin{array}{c}\text { Alcohol } \\
\text { consumption }\end{array}$ & $\begin{array}{l}\text { Alcohol } \\
\text { policy }\end{array}$ & $\begin{array}{l}\text { Liver cirr. } \\
\text { mortality }\end{array}$ & $\begin{array}{c}\text { Alcohol } \\
\text { consumption }\end{array}$ & $\begin{array}{l}\text { Alcohol } \\
\text { policy }\end{array}$ \\
\hline Austria & 29.2 & 13.8 & 6.0 & 19.7 & 11.1 & 7.0 \\
\hline Belgium & 12.9 & 13.5 & 8.5 & 11.8 & 10.3 & 11.5 \\
\hline Denmark & 11.4 & 11.5 & 7.0 & 14.0 & 11.7 & 8.5 \\
\hline Finland & 6.8 & 7.9 & 18.5 & 11.5 & 8.6 & 14.5 \\
\hline France & 28.9 & 19.2 & 9.5 & 13.4 & 12.9 & 12.5 \\
\hline Germany & - & 14.0 & 6.0 & 17.5 & 12.4 & 8.0 \\
\hline Greece & 10.6 & 13.2 & 2.0 & 5.0 & 9.4 & 7.0 \\
\hline Ireland & 4.7 & 10.5 & 12.0 & 4.3 & 13.7 & 12.0 \\
\hline Italy & 32.9 & 16.7 & 12.0 & 14.1 & 9.0 & 13.0 \\
\hline Netherlands & 5.1 & 11.5 & 11.0 & 5.1 & 10.1 & 13.0 \\
\hline Norway & 5.8 & 5.9 & 19.0 & 5.0 & 6.3 & 17.0 \\
\hline Portugal & 33.2 & 14.9 & 4.0 & 15.7 & 13.0 & 8.0 \\
\hline Spain & 24.2 & 18.5 & 4.5 & 10.8 & 11.5 & 10.0 \\
\hline Sweden & 11.2 & 7.1 & 18.5 & 5.2 & 6.0 & 16.5 \\
\hline Switzerland & 12.6 & 13.4 & - & 7.5 & 11.1 & - \\
\hline UK & 4.6 & 9.6 & 14.0 & 9.7 & 10.4 & 13.0 \\
\hline Average & 15.6 & 12.6 & 10.2 & 10.6 & 10.5 & 11.4 \\
\hline Std.err. & $(2.80)$ & $(0.95)$ & $(1.42)$ & $(1.23)$ & $(0.56)$ & $(0.84)$ \\
\hline
\end{tabular}

Notes: The annual mortality rate is measured per 100.000 inhabitants and alcohol consumption is the number of (pure) alcohol litres per inhabitant ( +15 years). Alcohol policy is a measure of the 'restrictiveness' of alcohol policies, measured on a 1-20 scale.

Sources: The World Health Organization (the WHOSIS database), World Drink Trends (1999, 2005), Karlsson and Österberg (2001).

There appears to be a rather close correlation between liver cirrhosis mortality and the intake of alcohol, but also a decline in the average level of liver cirrhosis mortality is seen from 1980 to 2000. The strictness of the alcohol policies in Europe seems to exhibit some convergence with approximately the same average value of the policy-variable, but with a decreasing standard error. Although there is an inverse relationship between the 
'strictness' of the policy and the level of alcohol consumption, the causal link between alcohol policy and alcohol consumption is most likely bi-directional. Heavy drinking may cause politicians to increase alcohol taxation or restrict sales to state-monopoly outlets but the causation may also be the opposite way so restrictive alcohol policies keep the alcohol intake at low levels.

Previous papers dealing with the estimation of the cirrhosis-alcohol relationship usually apply a semi-logarithmic specification based on a convex function between the risk of liver cirrhosis and alcohol consumption, cf. Ramstedt (2001) and Mills (2007). Additionally, only the present level of alcohol consumption is often included as an explanatory variable and thus assuming a contemporaneous effect from the intake of alcohol to cirrhosis mortality - which is not in accordance with expectations. Still, it normally takes several years to develop harmful liver cirrhosis which may eventually imply mortality. Liver cirrhosis may also be caused by other factors - just as alcohol may cause additional health problems besides cirrhosis mortality, cf. Rehm et al. (2003), Nordström and Ramstedt (2005) and Day (2006). Standard economic theory would predict alcohol demand influenced by income and prices of alcoholic beverages along the 'strictness' of alcohol policies. The latter is also influenced by the level of alcohol consumption due to the harmful social and health effects related to alcohol and therefore it blurs the causal link between alcohol consumption and alcohol policy.

In the empirical analysis we follow the standard procedure by estimating a semilogarithmic relationship like equation (1) with notation as used when dealing with panel data:

$$
\log _{i, t}=\alpha+\beta A_{i, t}+\varepsilon_{i, t}
$$

Due to the fact that liver cirrhosis takes time - probably years - to develop into a serious health threat, the average level of alcohol consumption during a ten-year period prior to 
the liver cirrhosis variable $\left(\mathrm{L}_{\mathrm{t}}\right)$ is also included as the explanatory variable ${ }^{2}$ in equation (1). The interpretation of the $\beta$-parameter is a semi-elasticity with the estimated value of $\beta$ expressing the relative increase in liver cirrhosis mortality due to a unit (one litre) increase in alcohol consumption:

$d \log L=\beta d A$

In line with equation (1) and equation (2) the panel data for sixteen European countries are depicted in Figure 1 as a scatter plot of the logs of cirrhosis mortality and alcohol consumption, the latter being ten-year average values (A10). A rather close correlation appears between the cirrhosis mortality rate and alcohol consumption ${ }^{3}-$ with some shifts in levels between the country-specific data and therefore a fixed-effects estimator will probably do well in this case, and likewise table 1 is revealing differences in the strictness of alcohol policies which also is an argument for country specific fixed effects.

\footnotetext{
${ }^{2}$ The notation will be A10 for the ten-year average value of alcohol consumption, and for the respective beverages - beer, wine and spirit - similar ten-year average values will be used in the estimations.

${ }^{3}$ Also longer lags have been investigated for and models with decreasing weights for lagged alcohol consumption have been included in the estimations - but the results do not differ much from the obtained results when using the average level of alcohol consumption during the most recent decade (A10).
} 
Figure 1. Plot of liver cirrhosis (log values) and alcohol consumption (litres per capita, annually).

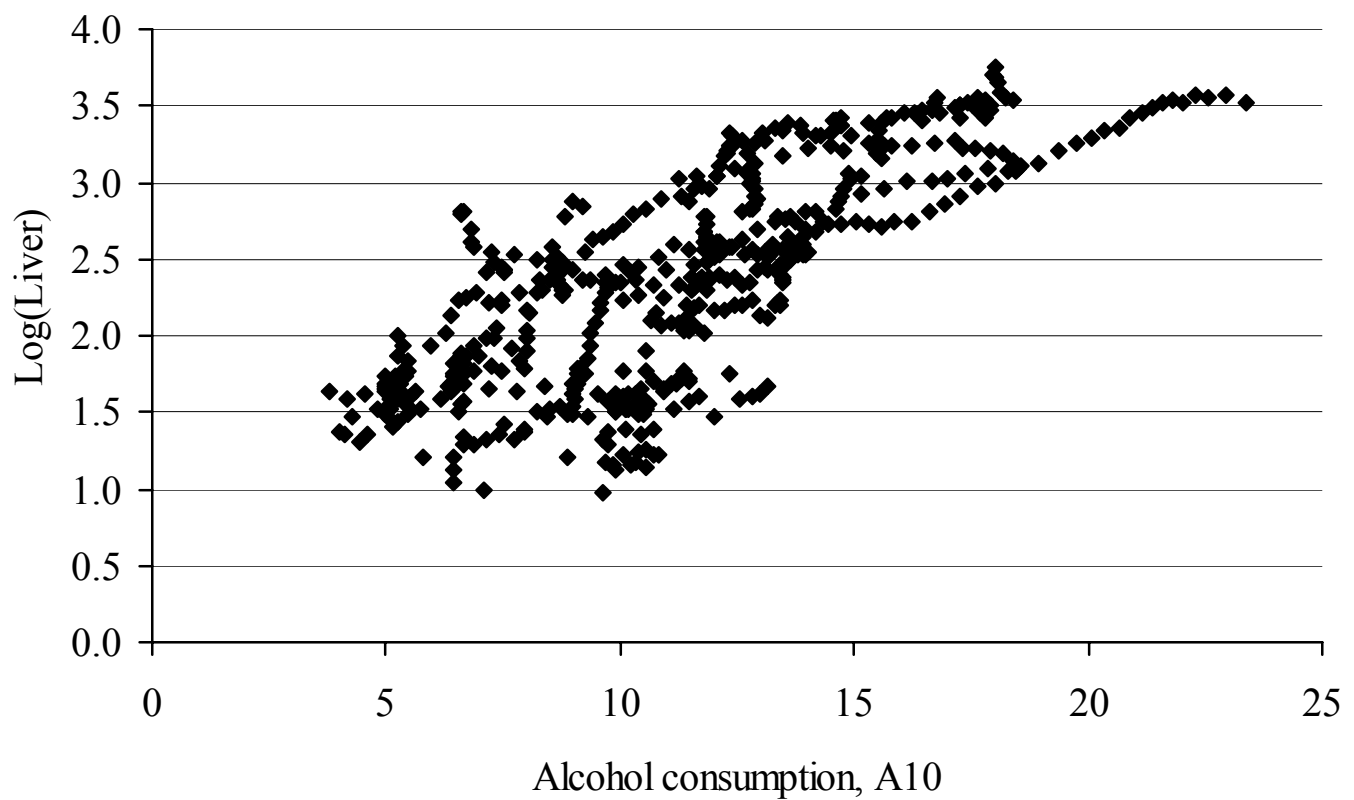

Notes: Panel data covering 16 countries and the time period 1970-2006 are used in the graph. Alcohol consumption (A10) is calculated as a 10-year average value and as the data for alcohol consumption covers the time period 1961-2006 there is no loss in the number of observations compared to using the contemporaneous alcohol consumption variable.

Many economic variables show up in empirical tests with a unit root in level values, i.e. a non-stationary behaviour, and a priori there should be no reason to exclude the same time-series properties for alcohol consumption and liver cirrhosis. Hence, these variables are investigated with respect to a unit root using the panel data test methodology from Im et al. (2003). This IPS-test is done as single equation ADF-tests with the test-statistic as an average $t$-value where critical values for varying panel sizes with respect to $\mathrm{N}$ and $\mathrm{T}$ are tabulated in Im et al. (2003). The results are exhibited in table 2, where also a trendstationary alternative is included ('Constant, Trend' in table 2) when testing the respective variables for a unit root. 
Table 2. Panel unit root test result; liver cirrhosis mortality and alcohol consumption, 1970-2006.

\begin{tabular}{|c|c|c|c|}
\hline & IPS test statistic & Critical values (5\%) & Lags \\
\hline \multicolumn{4}{|l|}{ Liver cirrhosis: } \\
\hline Constant & -0.31 & -1.90 & 0 \\
\hline Constant, Trend & $-2.70^{*}$ & -2.53 & 0 \\
\hline \multicolumn{4}{|l|}{$\begin{array}{l}\text { Alcohol } \\
\text { consumption: }\end{array}$} \\
\hline Constant & -1.44 & -1.50 & 2 \\
\hline Constant, Trend & -2.26 & -2.53 & 2 \\
\hline \multicolumn{4}{|l|}{$\begin{array}{l}\text { Alcohol } \\
\text { consumption, }(10- \\
\text { year average): }\end{array}$} \\
\hline Constant & $-1.93 *$ & -1.90 & 1 \\
\hline Constant, Trend & $-3.58^{*}$ & -2.53 & 1 \\
\hline
\end{tabular}

Notes: The number of lags $(0,1$ or 2$)$ selected from the AIC/SBC information criteria and all variables in $\operatorname{logs}$ (the same conclusions appear from using values without log). The 5 per cent critical values (for $\mathrm{N}=15$, $\mathrm{T}=30$ ) from Im et al. (2003) and a * indicates significance at this level.

The conclusion is rather clear as the critical value for the 5 percent level of significance is approximately -2.53 and when including a trend the test statistics for liver cirrhosis and alcohol consumption (ten-year average) both exceed this level - and hence a hypothesis of trend-stationarity cannot be rejected. Only including an intercept in the unit root test cannot reject the null hypothesis of non-stationarity, except in case of the alcohol consumption variable (ten-year average). Therefore, when estimating models as equation (1) in level values, deterministic trends need to be included in order to avoid problems related to spurious regressions, and the following modelling methodologies will consequently be adjusted to include time trends.

According to Mills (2007) the log-linear model (1) is performing better - in this case for a UK data set - than the alternatives like a linear or a fully logarithmic specification which explains the wide use of the form stated in equation (1). As an alternative to the log-linear specification a more general model based on the non-linear Box-Cox transformation of the variables is also applied in the present analysis in order not to 
impose too many restrictions a priori on the cirrhosis-alcohol relationship. With a fixed effects estimator - in the form of country specific dummies $\omega_{i}$ - for the panel data, the specification will be as given by equation (3) where also individual trends are included as a consequence from the unit root test:

$$
\begin{aligned}
& \frac{L_{i, t}^{\lambda_{L}}-1}{\lambda_{L}}=\alpha+\omega_{i}+\delta_{i} t+\beta \frac{A_{i, t}^{\lambda_{A}}-1}{\lambda_{A}}+\varepsilon_{i, t} \quad \lambda_{L}, \lambda_{A} \in[0 ; 1] \\
& \omega_{i}=\left\{\begin{array}{l}
1 \text { for ith country, } \mathrm{i}=2, \ldots, \mathrm{N} \\
0 \text { otherwise }
\end{array}\right.
\end{aligned}
$$

With a $\lambda$-parameter equal to 0 the Box-Cox transformation is simply the log-value and when $\lambda$ equals 1 the model is specified in absolute values. Thus, the log-linear model is a special case corresponding to $\lambda_{\mathrm{L}}=0$ and $\lambda_{\mathrm{A}}=1$, and therefore, allowing the $\lambda$-values to vary between 0 and 1 allows for a model specification ranging from fully logarithmic to absolute values. The non-linear equation (3) is estimated by a maximum-likelihood iteration procedure where the maximum of the likelihood function ${ }^{4}$ is chosen as the preferred model.

Due to the non-linear specification the size of the estimated parameters cannot be interpreted directly or compared to e.g. parameter estimates from a fixed effects estimator of equation (1). The semi-elasticity and the full elasticity can be derived from equation (3) and the specific values of the elasticities can be calculated from the parameter estimates from equation (1) or equation (3). The marginal effect on liver cirrhosis mortality from a change in alcohol consumption - measured as a semi-elasticity - is given by expression (4):

$$
\frac{d L}{L}=\beta \frac{1}{L^{\lambda_{L}} A^{1-\lambda_{A}}} d A
$$

\footnotetext{
${ }^{4}$ The likelihood function for the Box-Cox transformation can be found in e.g. Greene (1993) or Pindyck \& Rubinfeld (1998). Greene comments on using two $\lambda$-values like equation (3) as 'more cumbersome than necessary', but a common $\lambda$-value would preclude a model like (1).
} 
The level values of cirrhosis and alcohol consumption enter the expression for the semielasticity, which will reduce to expression (2) for the log-linear model with $\lambda$-values of 0 and 1, respectively. The full elasticity between liver cirrhosis mortality and alcohol consumption is given by (5):

$$
\varepsilon_{(L, A)}=\beta \frac{A^{\lambda_{A}}}{L^{\lambda_{L}}}
$$

When both $\lambda$-values equal 0 , i.e. a fully logarithmic model, the elasticity is $\beta$, but in all other cases the level values of one or both variables enter the calculation of the elasticity.

\section{Estimating alcohol-related liver cirrhosis mortality}

For the models presented in part 3 it is assumed that the $\beta$-parameters in the equations (1) and (3), respectively, are identical across countries. The alcohol-parameter is not of a traditional behavioural character but more influenced by medical causes and probably with rather high variation among individuals - but smaller or no differences should be expected when using aggregate data. The parameter estimates are reported in table 3 for three different versions of a fixed effects model. The first column reports the parameter estimates for the usually applied fixed effects case including time-specific dummies and in the second column individual trends - in accordance with the trend-stationary conclusion from the unit root tests - are included in model. The result from estimating the non-linear model from equation (3) is reported in the last column. 
Table 3. Fixed Effects and Nonlinear Fixed Effects parameter estimates using pooled panel data for 16 European countries, 1970-2006.

\begin{tabular}{lcccc} 
& $\begin{array}{c}\text { FE } \\
\text { (Indiv., Time) }\end{array}$ & $\begin{array}{c}\text { FE } \\
\text { (Indiv., Trend) }\end{array}$ & $\begin{array}{c}\text { Nonlin FE } \\
\text { (Indiv., Trend) }\end{array}$ \\
\hline$\beta$ & $0.097^{*}(0.006)$ & $0.044^{*}(0.006)$ & $0.078^{*}(0.012)$ \\
$\hat{\lambda}_{L}$ & - & - & $0.289^{*}(0.011)$ \\
$\hat{\lambda}_{A}$ & - & - & $1.00 \quad(-)$ \\
Semi-elasticity & 0.097 & 0.044 & 0.039 \\
Elasticity & 1.019 & 0.462 & 0.414 \\
\hline
\end{tabular}

Notes: Fixed effects estimation with individual and time dummies (left column), fixed effects including individual trends, both linear and nonlinear (equation 3). The alcohol consumption variable used is a tenyear average value (A10). Elasticities calculated from equation 4 and equation 5 (with average values of liver cirrhosis mortality and alcohol consumption from year 2000). In parenthesis the standard errors of the parameter estimates are reported, with a * indicating significance at least at the five per cent level.

The inclusion of individual trends in the FE estimation results in a much lower parameter estimate (0.044) compared to the FE model with time dummies (0.097), with the former as the preferred model as this is in consistency with the trend-stationary alternative from table 2 . The parameter estimates for the $\lambda$-values in the nonlinear case seem close to $(0$, 1)-values, which would correspond to the usual log-linear model from equation (1), but the estimate of $\lambda_{\mathrm{L}}$ is deviating significantly from zero and hence, formally such a hypothesis would be rejected. When calculating the actual elasticities in the cirrhosisalcohol models - as reported in table 3 - there is no difference between an FE and a nonlinear FE as long as the individual trends are allowed for ${ }^{5}$. Thus, alcohol consumption does have a significant influence on cirrhosis mortality and the values of the $\beta$-parameter estimates is also in accordance with other studies, e.g. Ramstedt (2001) using pooled data in differences, but the trend-inclusion approximately halves the level-value of the $\beta$ parameter.

\footnotetext{
${ }^{5}$ In order to further investigate the robustness and appropriateness of estimating the model from equation (3) parameter estimates are reported in Appendix 1 for a random effects model as well as a first difference model and there seems to be no major differences between the estimators.
} 
The country specific trends in liver cirrhosis mortality, which are resulting from the FE estimation of equation (3) are shown in figure 2 as a scatter plot against the changes in alcohol policies.

Figure 2. A scatter plot of country specific trends from the FE model and the changes in alcohol policies.

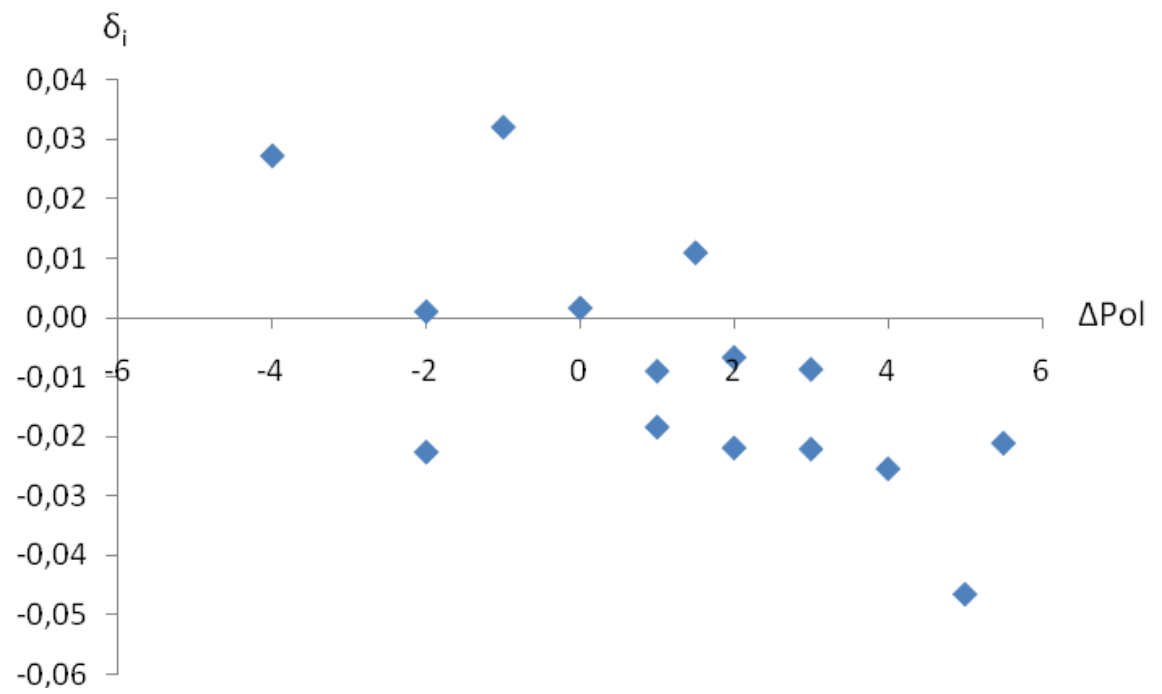

Note: The horizontal axis depicts the changes in alcohol policies from 1980 to 2000 as presented in table 1, and the vertical axis is depicting the values of the individual trend parameters $\delta_{\mathrm{i}}$ from equation (3).

Noting that positive changes in alcohol policy indicates tightening of the policy, the figure shows a clear negative relationship between a more restrictive policy and the trend in the fixed effects model of liver cirrhosis mortality. ${ }^{6}$ Therefore, as a more restrictive policy change from 1980 to 2000 is correlated with a smaller trend parameter value this might indicate that alcohol polices do affect health conditions, including liver cirrhosis. As the alcohol consumption variable is already included in equation (3) - along the fixed effects from country-specific conditions - there seems to be an additional influence from alcohol policies on cirrhosis mortality. This effect is most likely due to changes in the drinking behaviour, e.g. alcohol is more related to being enjoyed with meals and avoiding

\footnotetext{
${ }^{6}$ A linear regression for the data points in figure 2 will give a significant negative slope and a value of 0.44 for the adjusted $R^{2}$.
} 
heavy drinking or bunch drinking behaviour ${ }^{7}$, more information directed towards high risk groups etc. It may also involve other health improving initiatives that lowers cirrhosis mortality where the countries with an (initial) high level of cirrhosis mortality in the 1960s also show up with a smaller trend parameter value in equation (3) compared with other countries.

\section{Effects on cirrhosis mortality from beer, wine and spirits consumption}

The total consumption of alcohol can be broken down into beer, wine and spirits - all measured in liters of pure alcohol - and hence the log-linear model (1) including individual fixed effects as well as individual trends can be partitioned into the specific beverages appearing as explanatory variables:

$$
\log _{i, t}=\alpha+\omega_{i}+\delta_{i} t+\beta_{B} B_{i, t}+\beta_{W} W_{i, t}+\beta_{S} S_{i, t}+\varepsilon_{i, t}
$$

As the sum of the beer, wine and spirits consumption add up to total alcohol consumption (all measured in litres of pure alcohol) the same parameter values for $\beta$ should be expected - unless beverage-specific effects are taking place concerning liver cirrhosis mortality. The latter is often the case in the literature when e.g. the conclusion is that cirrhosis mortality is highly related to or caused by wine or spirits.

In accordance with the estimation procedure from part 4 the beverages are all measured as ten-year average values where the panel unit root test again comes up in favour of a trend-stationary alternative - and thus, individual trends are included in equation (6). There will most likely be a problem of multicollinearity when estimating equation (6) as the consumption of beer, wine and spirits might be correlated. Investigating for partial correlations reveal that beer and spirits are the most correlated beverages and hence models only including one of these beverages are also estimated - as reported in table 4.

\footnotetext{
${ }^{7}$ An opposite argument is that consuming alcohol regularly, e.g. on a daily basis as in Southern European countries, is harmful to the liver as it is treating alcohol continuously - compared to episodic drinking behaviour, although the latter may involve the same total amount of alcohol consumed.
} 
Table 4. Parameter estimates from beverage specific models (with individual fixed effects and trends).

\begin{tabular}{|c|c|c|c|c|c|}
\hline & $\beta_{\text {beer }}$ & $\beta_{\text {wine }}$ & $\beta_{\text {sptrts }}$ & SSR & $\bar{R}^{2}$ \\
\hline \multicolumn{6}{|l|}{ Model: } \\
\hline $\begin{array}{l}\text { Beer, Wine, } \\
\text { Spirits }\end{array}$ & $\begin{array}{l}0.099 * \\
(0.020)\end{array}$ & $\begin{array}{l}0.046^{*} \\
(0.016)\end{array}$ & $\begin{array}{l}-0.010 \\
(0.021)\end{array}$ & 5.08 & 0.98 \\
\hline Beer, Wine & $0.096^{*}$ & $\begin{array}{l}0.043^{*} \\
(0.015)\end{array}$ & - & 5.18 & 0.98 \\
\hline Wine, Spirits & - & $\begin{array}{c}0.044 \\
(0.016)\end{array}$ & $\begin{array}{l}0.061^{*} \\
(0.016)\end{array}$ & 5.35 & 0.98 \\
\hline Beer & $\begin{array}{l}0.104^{*} \\
(0.014)\end{array}$ & - & - & 5.27 & 0.98 \\
\hline Wine & - & $\begin{array}{l}0.060^{*} \\
(0.015)\end{array}$ & - & 5.65 & 0.97 \\
\hline Spirits & - & - & $\begin{array}{l}0.072^{*} \\
(0.016)\end{array}$ & 5.43 & 0.88 \\
\hline
\end{tabular}

Notes: In parenthesis the standard errors of the parameter estimates are reported, with a * indicating significance at least at the five per cent level. SSR is the sum of squared residuals. Ten-year average values are used for the consumption of the three beverages.

When including all drinks in the model spirits shows up with an insignificant parameter estimate, but this is probably related to the appearance of multicollinearity. The parameter estimates seem more robust when only one or two beverages are included in the model specification. Hence, the most likely conclusion is that all three beverages are having an effect on liver cirrhosis mortality - and beer may even have the highest effect.

An interesting conclusion in some studies is that cirrhosis mortality is highly related to the consumption of wine, see e.g. Mills (2007), which is not quite in accordance with the present analysis where wine shows up with the smallest parameter estimates (table 4). Other studies find spirits to be the most cirrhosis-causing beverage, cf. e.g. Kerr et al. (2000) and Stokkeland (2006), but beer is usually assumed to be less harmful. From an extensive micro data set Becker et al. (2002) find increasing alcohol intake to be related to cirrhosis effects, but wine drinkers have a lower risk of cirrhosis than beer and spirits drinkers. The share of wine in the total alcohol consumption is found to be high in Southern Europe as well as for some Northern European countries where the overall level 
of wine consumption has increased remarkably during recent decades. The interpretation that wine is the primary cause in relation to liver cirrhosis may be erroneous in the sense that it is the alcohol content, not the drink per se that causes the detrimental health consequences. It must be expected that all kinds of alcohol should cause liver cirrhosis and other diseases, but naturally the drinking habits (e.g. wine enjoyed with a meal) might also be of influence.

Alcohol consumption is usually assumed to be related to income and prices - as well as other variables - and if e.g. one of the beverages is relatively cheaper than other alcoholic beverages this might be preferred by the heavy drinkers mostly exposed to liver cirrhosis, and this beverage should show up with a high parameter estimate in table 4 . Appendix 2 exhibits some recent price levels of the beverages in the sixteen European countries, and there does seem to be some variation in the relative prices of the drinks in the respective countries which may have some price effects concerning the drinking patterns and hence, also some cirrhosis mortality consequences. All of the three beverages influence liver cirrhosis - and significantly, according to the parameter estimates in table 4 - and thus, in relation to the health consequences it might be less important in what directions the relative beverage prices influence the drinking patterns.

\section{Conclusion}

This article analyses the relationship between alcohol consumption and the negative impacts on health in terms of liver cirrhosis mortality. Using panel data covering twentyfive years at an aggregate level for sixteen European countries in the present study leaves no doubt about the detrimental health effects of alcohol intake. At the individual level liver cirrhosis is a consequence of sustained heavy drinking during several years and one of the conclusions from the analysis gives support to a model where alcohol consumption during the most recent decade is included as an explanatory variable concerning cirrhosis mortality. This specification is different from the majority of studies dealing with the alcohol-cirrhosis mortality topic because normally the actual consumption level of alcohol is included as an explanatory variable in the econometric specification. The 
variables for alcohol consumption and cirrhosis mortality are also investigated for unit roots where the conclusion from panel unit root tests indicate these variables to be best described as trend-stationary. Hence, the modeling procedure involves country-specific trends in all versions of the panel data estimators. Additionally, the modeling procedure is also including a non-linear Box-Cox specification where flexibility is allowed for in the sense that the model may be fully logarithmic, semi-logarithmic or having no logarithmic transformation at all - estimated by an iterative maximum likelihood procedure and including fixed effects. The usual methodology in the literature on cirrhosis mortality is a semi-log model where the ML-estimation for the panel data for the sixteen European countries exhibits a model deviating somewhat from the semi-log specification - but the implied elasticities in the alcohol-cirrhosis relationship do not differ much from a fixed effects model. The implications from the panel unit root analysis seem to be more important as the inclusion of country-specific trends in a fixed effects model will approximately half the parameter estimates. Therefore, the results concerning the impact from alcohol consumption to cirrhosis mortality are influenced from the less restrictive modeling procedure. Generally, the elasticities between alcohol consumption and liver cirrhosis mortality are higher when evaluated from the parameter estimates using the non-linear ML-estimation procedure in comparison to a semi-log model. Furthermore the cirrhosis mortality seems to be affected negatively by changes in alcohol policy in a more restrictive way after controlling for the alcohol consumption level, suggesting that the alcohol policy has health implications both by reducing consumption levels and by having a direct effect by affecting drinking habits, i.e. the frequency and time distribution of drinks.

A particular issue of importance is whether all the specific beverages influence on cirrhosis mortality, where predominantly spirits and wine are assumed to have harmful effects according to most empirical studies. The present analysis suggests that also beer has a significant impact, i.e. all three beverages have significant influence on liver cirrhosis mortality, which is also consistent with a medical fact of alcohol causing liver cirrhosis. Clearly, future research topics should address the impacts from the specific 
beverages as well as apply varying model specifications as the results and conclusions seem to vary relatively much depending on the econometric methodology.

\section{References}

Anderson, P. and B. Baumberg (2006): Alcohol in Europe - A public health perspective. A Report for the European Commission, Institute of Alcohol Studies, UK.

Antoñanzas, F., R. Rodríguez-Ibeas, E. Barco, M. Ramírez and M. Pinillos (2008): Alcohol consumption in the EU: health economics and policy issues under a permanent debate. European Journal of Health Economics, 9, 1-6.

Becker, U., M. Groenbaek, D. Johansen and T. I. A. Soerensen (2002): Lower Risk for AlcoholInduced Cirrhosis in Wine Drinkers. Hepatology, 35, 868-875.

Day, C. P. (2006): Alcohol and the liver. Medicine, 35, 22-25.

de Lorimier, A. A. (2000): Alcohol, Wine, and Health. The American Journal of Surgery, 180, 357-361.

Gmel, G., J. Rehm and U. Frick (2001): Methodological Approaches to Conducting Pooled Cross-Sectional Time Series Analysis: The Example of the Association between All-Cause Mortality and per capita Alcohol Consumption for Men in 15 European States. European Addiction Research, 7, 128-137.

Gutjahr, E., G. Gmel and J. Rehm (2001): Relation between Average Alcohol Consumption and Disease: An Overview. European Addiction Research, 7, 117-127.

Greene, W.H. (1993): Econometric Analysis, Prentice Hall.

Im, K. S., M. H. Pesaran and Y. Shin (2003): Testing for unit roots in heterogeneous panels. Journal of Econometrics, 115, 53-74. 
Karlsson, T. and E. Österberg (2001): A scale of formal alcohol control policy in 15 European countries. Nordisk Alkohol- og Narkotikatidskrift (English Supplement), 18, 117-131.

Kerr, W. C., K. M. Fillmore and P. Marvy (2000): Beverage-specific alcohol consumption and cirrhosis mortality in a group of English-speaking beer-drinking countries. Addiction, 95, 339346, (Four commentaries, 347-358).

Mäkelä, P., G. Gmel, U. Grittner, H. Kuendig, S. Kuntsche, K. Bloomfield and R. Room (2006): Drinking patterns and their gender differences in Europe. Alcohol \& Alcoholism, 41 (Supp. 1), i8i18.

Mills, T. C. (2007): Liver cirrhosis and alcohol consumption in the U.K.: time series modeling of recent trends. Statistical Modelling, 7, 91-103.

Mumenthaler, M. S., J. L. Taylor, R. O'Hara and J. E. Yesavage (1999): Gender Differences in Moderate Drinking Effects. Alcohol Research and Health, 23, 55-61.

Norström, T. (1989): The Use of Aggregate Data in Alcohol Epidemiology. British Journal of Addiction, 84, 969-977.

Norström, T. and Ole-Jørgen Skog (2001): Alcohol and mortality: methodological and analytical issues in aggregate analyses. Addiction, 96 (Supplement), 5-17.

Norström, T. and M. Ramstedt (2005): Mortality and population drinking: a review of the literature. Drug and Alcohol Review, 24, 537-547.

Pindyck, R. S. and D. L. Rubinfeld (1998): Econometric Models and Economic Forecasts. McGraw-Hill.

Ramstedt, M. (2001): Per capita alcohol consumption and liver cirrhosis mortality in 14 European countries. Addiction, 96 (Supplement), 19-34.

Rehm, J. and G. Gmel (2001): Aggregate time-series regression in the field of alcohol. Addiction, 96, 945-954. 
Rehm, J, R. Room, K. Graham, M. Monteiro, G. Gmel and C. T. Sempos (2003): The relationship of average volume of alcohol consumption and patterns of drinking to burden of disease: an overview. Addiction, 98, 1209-1228.

Roizen, R., W. C. Kerr and K. M. Fillmore (1999): Cirrhosis mortality and per capita consumption of distilled spirits, United States, 1949-94: trend analysis. British Medical Journal, $319,666-70$.

Room, R., T. Babor and J. Rehm (2005): Alcohol and public health. The Lancet, 365, 519-30.

Stokkeland, K. (2006): Studies on alcoholic liver disease. Karolinska Institutet, Stockholm, Sweden.

The WHO Statistical Information System (WHOSIS, www.who.int).

World Drink Trends, 1999 Edition. NTC Publications Ltd., UK.

World Drink Trends, 2005 Edition. World Advertising Research Center Ltd., UK. 


\section{Appendix 1.}

The parameter estimates reported in table A1 are for the fixed effects and random effects models with country-specific trends and a first difference estimator in the last column.

Table A1. Fixed effects, random effects and first difference parameter estimates.

\begin{tabular}{lccc}
\hline & $\begin{array}{c}\text { Fixed Effects } \\
\text { (Indiv., Trend) }\end{array}$ & $\begin{array}{c}\text { Random Effects } \\
\text { (Indiv., Trend) }\end{array}$ & $\begin{array}{c}\text { First } \\
\text { Difference }\end{array}$ \\
\hline$\hat{\beta}$ & $0.044^{*}(0.006)$ & $0.047^{*}(0.006)$ & $0.066^{*}(0.016)$ \\
$\mathrm{SSR}$ & 5.29 & 5.29 & 4.01 \\
$\bar{R}^{2}$ & 0.98 & 0.98 & 0.03 \\
Hausman-test & - & $14.65[0.48]$ & - \\
\hline
\end{tabular}

Notes: The FE and RE models include country-specific trends. Liver cirrhosis mortality in logs and alcohol consumption in absolute values (a ten year average value) and in parenthesis the standard errors of the parameter estimates are reported, with $\mathrm{a} *$ indicating significance at least at the five per cent level. For the RE models a Hausman specification test is reported with $p$-values in parenthesis. 


\section{Appendix 2.}

Table A2. Average prices for drinks in sixteen European countries 2003-2006, Euros per drink (2005 prices).

\begin{tabular}{llll}
\hline & Beer & Wine & Spirits \\
\hline Austria & 0.27 & 0.30 & 0.40 \\
Belgium & 0.33 & 0.40 & 0.38 \\
Denmark & 0.32 & 0.47 & 0.64 \\
Finland & 0.67 & 0.75 & 0.60 \\
France & 0.34 & 0.41 & 0.35 \\
Germany & 0.19 & 0.24 & 0.27 \\
Greece & 0.38 & 0.64 & 0.58 \\
Ireland & 0.70 & 1.07 & 0.77 \\
Italy & 0.29 & 0.24 & 0.29 \\
Netherlands & 0.30 & 0.31 & 0.41 \\
Norway & 1.08 & 1.18 & 1.23 \\
Portugal & 0.29 & 0.26 & 0.32 \\
Spain & 0.27 & 0.16 & 0.32 \\
Sweden & 0.44 & 0.89 & 0.91 \\
Switzerland & 0.41 & 0.78 & 0.50 \\
United Kingdom & 0.58 & 0.72 & 0.53 \\
\hline
\end{tabular}

Notes: The price of drinks calculated as an average price level for 2003 to 2006 from annual data (constant 2005 prices).

Source: Euromonitor International, 2009. 
Department of Economics:

Skriftserie/Working Paper:

2009:

WP 09-1 Tomi Kyyrä, Pierpaolo Parrotta and Michael Rosholm: The Effect of Receiving Supplementary UI Benefits on Unemployment Duration ISBN 9788778824035 (print); ISBN 9788778824042 (online)

WP 09-2 Dario Pozzoli and Marco Ranzani: Old European Couples' Retirement Decisions: the Role of Love and Money ISBN 9788778824165 (print); ISBN 9788778824172 (online)

WP 09-3 Michael Gibbs, Mikel Tapia and Frederic Warzynski: Globalization, Superstars, and the Importance of Reputation: Theory \& Evidence from the Wine Industry ISBN 9788778824189 (print); ISBN 9788778824196 (online)

WP 09-4 Jan De Loecker and Frederic Warzynski: Markups and FirmLevel Export Status ISBN 9788778824202 (print); ISBN 9788778824219 (online)

WP 09-5 Tor Eriksson, Mariola Pytliková and Frédéric Warzynski: Increased Sorting and Wage Inequality in the Czech Republic: New Evidence Using Linked Employer-Employee Dataset ISBN 9788778824226 (print); ISBN 9788778824233 (online)

WP 09-6 Longhwa Chen and Tor Eriksson: Vacancy Duration, Wage Offers, and Job Requirements - Pre-Match Data Evidence ISBN 9788778824240 (print); ISBN 9788778824257 (online)

WP 09-7 Tor Eriksson, Valérie Smeets and Frédéric Warzynski: Small Open Economy Firms in International Trade: Evidence from Danish Transactions-Level Data ISBN 9788778823861 (print); ISBN 9788778823878 (online)

WP 09-8 Dario Pozzoli and Marco Ranzani: Participation and Sector Selection in Nicaragua ISBN 9788778823885 (print); ISBN 9788778823892 (online) 
WP 09-9 Rikke Ibsen, Frederic Warzynski and Niels Westergård-Nielsen: Employment Growth and International Trade: A Small Open Economy Perspective ISBN 9788778823908 (print); ISBN 9788778823915 (online)

WP 09-10 Roger Bandick and Holger Görg: Foreign acquisition, plant survival, and employment growth ISBN 9788778823922 (print); ISBN 9788778823939 (online)

WP 09-11 Pierpaolo Parrotta and Dario Pozzoli: The Effect of Learning by Hiring on Productivity

ISBN 9788778823946 (print); ISBN 9788778823953 (online)

WP 09-12 Takao Kato and Pian Shu

Peer Effects, Social Networks, and Intergroup

Competition in the Workplace

ISBN 9788778823984 (print); ISBN 9788778823991 (online)

WP 09-13 Sanne Hiller and Erdal Yalcin: Switching between Domestic Market Activity, Export and FDI

ISBN 9788778824004 (print); ISBN 9788778824028 (online)

WP 09-14 Tor Eriksson and Mariola Pytlikova: Foreign Ownership Wage Premia in Emerging Economies: Evidence from Czech Republic ISBN 9788778824035 (print); ISBN 9788778824042 (online)

WP 09-15 Astrid Würtz Rasmussen: Family Structure Changes and Children's Health, Behavior, and Educational Outcomes ISBN 9788778824059 (print); ISBN 9788778824066 (online)

WP 09-16 Tor Eriksson: How Many Danish Jobs Can (Potentially) Be Done Elsewhere?

ISBN 9788778824073 (print); ISBN 9788778824080 (online)

WP 09-17 Lorenzo Cappellari, Claudio Lucifora and Dario Pozzoli: Determinants of Grades in Maths for Students in Economics ISBN 9788778824103 (print); ISBN 9788778824110 (online)

WP 09-18 Yingqiang Zhang and Tor Eriksson: Inequality of Opportunity and Income Inequality in Nine Chinese Provinces, 1989-2006 ISBN 9788778824127 (print); ISBN 9788778824134 (online) 
WP 09-19 Ricard Gil and Frederic Warzynski: Vertical Integration, Exclusivity and Game Sales Performance in the U.S. Video Game Industry ISBN 9788778824141 (print); ISBN 9788778824165 (online)

WP 09-20 Christian Gormsen: Intransparent Markets and Intra-Industry Trade ISBN 9788778824172 (print); ISBN 9788778824189 (online)

WP 09-21 Jan Bentzen and Valdemar Smith: Wine production in Denmark Do the characteristics of the vineyards affect the chances for awards?

ISBN 9788778824196 (print); ISBN 9788778824202 (online)

WP 09-22 Astrid Würtz Rasmussen: Allocation of Parental Time and the Long-Term Effect on Children's Education ISBN 9788778824233 (print); ISBN 9788778824240 (online)

2010:

WP 10-01 Marianne Simonsen, Lars Skipper and Niels Skipper:

Price Sensitivity of Demand for Prescription Drugs: Exploiting a Regression Kink Design ISBN 9788778824257 (print); ISBN 9788778824264 (online)

WP 10-02 Olivier Gergaud, Valérie Smeets and Frédéric Warzynski: Stars War in French Gastronomy: Prestige of Restaurants and Chefs'Careers ISBN 9788778824271 (print); ISBN 9788778824288 (online)

WP 10-03 Nabanita Datta Gupta, Mette Deding and Mette Lausten: Medium-term consequences of low birth weight on health and behavioral deficits - is there a catch-up effect? ISBN 9788778824301 (print); ISBN 9788778824318 (online)

WP 10-04 Jørgen Drud Hansen, Hassan Molana, Catia Montagna and Jørgen Ulff-Møller Nielsen: Work Hours, Social Value of Leisure and Globalisation ISBN 9788778824332 (print); ISBN 9788778824349 (online)

WP 10-05 Miriam Wüst: The effect of cigarette and alcohol consumption on birth outcomes ISBN 9788778824455 (print); ISBN 9788778824479 (online) 
WP 10-06 Elke J. Jahn and Michael Rosholm:Looking Beyond the Bridge: How Temporary Agency Employ-ment Affects Labor Market Outcomes ISBN 9788778824486 (print); ISBN 9788778824493 (online)

WP 10-07 Sanne Hiller and Robinson Kruse: Milestones of European Integration: Which matters most for Export Openness? ISBN 9788778824509 (print); ISBN 9788778824516 (online)

WP 10-08 Tor Eriksson and Marie Claire Villeval: Respect as an Incentive ISBN 9788778824523 (print); ISBN 9788778824530 (online)

WP 10-09 Jan Bentzen and Valdemar Smith: Alcohol consumption and liver cirrhosis mortality: New evidence from a panel data analysis for sixteen European countries ISBN 9788778824547 (print); ISBN 9788778824554 (online) 